\title{
EDITORIAL
}

\section{What is the role of genetics in occupational asthma?}

\author{
C.E. Mapp
}

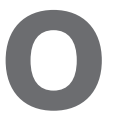

ccupational asthma (OA) is a disease characterised by variable airflow limitation and/or airway hyperresponsiveness, due to causes and conditions attributable to a particular occupational environment, and not to stimuli encountered outside the workplace [1]. There are two types of OA, which are caused by two distinct mechanisms: immunological and nonimmunological. The former appears after a latency period and is induced by an immunoglobulin (Ig)E-dependent mechanism (triggered by most high- and some low-molecular-weight agents) or an IgE-independent mechanism (triggered by most low-molecular-weight agents). The latter type of $\mathrm{OA}$ is characterised by the absence of a latency period and occurs after accidental exposure to high levels of a respiratory irritant at work or outside the workplace [2].

Although the exact cause of $\mathrm{OA}$ is not yet known, in general OA, similarly to nonoccupational asthma, may be caused by complex interactions between genes and the environment, including gene-environment, gene-gene, gene-gene-environment, and gene-environment-environment interactions [3].

What, then, is the role of genetics in subjects with OA? And where should research focus attention?

Addressing the second of these questions, asthma genetics has received much attention and has made much progress in recent decades. Importantly, the multifactorial pathogenesis of asthma has been recognised. That is, genetic research has shown that asthma behaves as a complex disease, and that it is not caused by single gene mutations [4]. These findings have opened important challenges for researchers. Among these challenges are identifying the genes involved in the disease, determining the mechanisms underlying the phenotype heterogeneity of the disease, and understanding how developmental and environmental factors interact with genetic determinants to affect disease susceptibility.

Another challenge is that many associations found in studies on the genetics of asthma have not been replicated in multiple populations. Why? What is the problem with genetics research? One reasonable explanation is put forward by OBER and THOMPSON [3]: instead of considering a negative study as evidence against a gene contributing to risk, it might be more

SUPPORT STATEMENT: This work was supported by the Ministry of University and Scientific Research, Associazione per la Ricerca e la Cura dell'Asma (ARCA; Padova, Italy) and the Consorzio Ferrara Ricerche (Ferrara, Italy).

STATEMENT OF INTEREST: None declared.

CORRESPONDENCE: C.E. Mapp, Dipartimento di Medicina Clinica e Sperimentale, Università degli Studi di Ferrara, Via Fossato di Mortara 64 B, 44100 Ferrara, Italy. Fax: 39 0532205066. E-mail: map@unife.it effective to consider why the gene is contributing to risk in some populations but not in others. As an example, the HLADQB1 ${ }^{*} 0501$ allele confers susceptibility to developing specific IgEs against organic acid anhydrides [5], but the same allele is protective for the low-molecular-weight agents diisocyanates and plicatic acid [6,7], suggesting that different affinities for the corresponding specific class-II molecules exist.

The lack of important associations and the inability to replicate results in genetic studies on asthma could also be due to the fact that most studies do not take into account the contribution from the environment. Environmental factors include the in utero environment during pregnancy, maternal health status, sex, endotoxin and inhaled aeroallergen exposure, tobacco smoke, diet, viral infections, exposure to sensitisers (types and levels of sensitiser, and timing of exposure) and irritants in the workplace.

Another reason that genetic studies have not come up with important associations may be that epigenetics is the link between our genes and the environment $[3,8]$. With this term, we define stable and heritable changes in gene expression that do not involve changes in DNA sequences [9]. Epigenetic mechanisms include DNA methylation, histone deacetylation and other modes of chromatin remodelling. They provide a means for the selective expression of a specific allele from one chromosome whereas the allele present on the partner chromosome remains silenced [10].

Because of the recent focus on asthma genetics, genetic testing has been recommended for screening and for monitoring patients. These recommendations raise ethical concerns about the use of genetic tests and about how implementation should be expanded. Thus, the ethical question is: what is the appropriate role of genetics in $\mathrm{OA}$ ?

There is no consensus of opinion about ethics; nevertheless, ethical issues must be considered. Theoretically, genetic testing could be used beneficially, for pre-employment decisions, employee placement, job replacement or relocation, and risk avoidance including implementation of control measures for harmful exposures in the workplace. However, caution is needed. Among the criteria required to perform genetic testing on workers, the first is that a genetic test for a specific condition (e.g. for $\mathrm{OA}$ ) must be highly specific and sensitive and must have a low incidence of both false-positives and false-negatives. In addition, the test must search for a gene that is sufficiently penetrant for the test result to have health implications [11,12]. So far, associations found in OA are modest with low odds ratios, indicating that genetic testing alone is not advisable for measuring risk for OA [13-15]. Furthermore, because asthma is a complex disease, caused by multiple genetic and environmental factors, information obtained to date by a single gene test 
is limited for both diagnostic and preventive purposes and, thus, cannot be recommended [16].

In addition to genetic testing being as yet unreliable, even reliable genetic testing would carry the risk of genetic discrimination, including loss of employment, promotion, insurance and healthcare [17]. Genetic discrimination and misuse of genetic information exist and are manifested in many social institutions, particularly in the health and life insurance industries [18]. More vigilance is needed in order to avoid creating a new social underclass based on genetic discrimination, the so-called "asymptomatic ill" [19].

What, then, can be done? One suggestion is that identifying genes of interest based on relevant exposures, rather than on disease outcomes, may be more useful in clarifying geneenvironment-disease interactions. Thus, there is heightened interest in the possibility that gene-environment interactions may be effective for understanding the mechanisms involved in occupational asthma. Unfortunately, we are not there yet. There is another issue: are we overemphasising the role of genes in disease causation? If the answer is yes, by doing this are we underestimating the role of environmental factors in disease causation? The answer is probably yes.

So, what comes next? Genes or environment? I can sum up my thinking by offering five points for consideration: 1) individuals are not just DNA codes; 2) environmental and occupational exposures must be taken into account in genetic studies on $\mathrm{OA} ; 3)$ reducing the exposure at the workplace is a priority; 4) collaborative studies between different research institutes and government agencies should be promoted with the aim of improving genetic testing in OA; and 5) researchers should always keep always in mind that $\mathrm{OA}$ is a preventable disease.

Genetics has the potential to do great good, although to date, it has had limited benefits for occupational asthma. Genetic discrimination, misuse of genetic information, and shifting the responsibility for a safe workplace from the employer to the employee should be avoided.

\section{ACKNOWLEDGEMENTS}

The author thanks M. Zeiger (Cardiovascular Research Institute, University of California San Francisco, San Francisco, CA, USA) for fine work throughout the revision of this manuscript.

\section{REFERENCES}

1 Vandenplas O, Malo JL. Definitions and types of workrelated asthma: a nosological approach. Eur Respir J 2003; 21: 706-712.
2 Mapp CE, Boschetto P, Maestrelli P, Fabbri LM. Occupational asthma. Am J Respir Crit Care Med 2005; 172: 280-305.

3 Ober C, Thompson EE. Rethinking genetic models of asthma: the role of environmental modifiers. Curr Opin Immunol 2005; 17: 670-678.

4 Vercelli D. Discovering susceptibility genes for asthma and allergy. Nat Rev Immunol 2008; 8: 169-182.

5 Jones MG, Nielsen J, Welch J, et al. Association of HLADQ5 and HLA-DR1 with sensitization to organic acid anhydrides. Clin Exp Allergy 2004; 34: 812-816.

6 Mapp CE, Beghè $\mathrm{B}$, Balboni $\mathrm{A}$, et al. Association between HLA genes and susceptibility to toluene diisocyanate-induced asthma. Clin Exp Allergy 2000; 30: 651-656.

7 Horne C, Quintana PJE, Keown PA, Dimich-Ward H, Chan-Yeung M. Distribution of DRB1 and DQB1 HLA class II alleles in occupational asthma due to western red cedar. Eur Respir J 2000; 15: 911-914.

8 Miller RL, Ho SM. Environmental epigenetics and asthma. Current concepts and call for studies. Am J Respir Crit Care Med 2008; 177: 567-573.

9 Jiang YH, Bressler J, Beaud AL. Epigenetics and human disease. Annu Rev Genomics Hum Genet 2004; 5: 479-519.

10 Steinke JW, Rich SS, Borish L. Genetics of allergic disease. J Allergy Clin Immunol 2008; 121: S384-S387.

11 MacDonald C, Williams-Jones B. Ethics and genetics: susceptibility testing in the workplace. J Business Ethics 2002; 35: 235-241.

12 Christiani DC, Mehta AJ, Yu CL. Genetic susceptibility to occupational exposures. Occup Environ Med 2005; 65: 430-436.

13 Mapp CE. The role of genetic factors in occupational asthma. Eur Respir J 2003; 22: 173-178.

14 Mapp CE. Genetics and the occupational environment. Curr Opin Allergy Clin Immunol 2005; 5: 113-118.

15 Park HS, Frew AJ. Genetic markers for occupational asthma. J Allergy Clin Immunol 2002; 109: 774-776.

16 Koppelman GH, te Meerman GJ, Postma DS. Genetic testing for asthma. Eur Respir J 2008; 32: 775-782.

17 Billings PR. Genetic nondiscrimination. Nat Genet 2005; 37: 559-560.

18 Billings PR, Kohn MA, de Cuevas M, Beckwith J, Alper JS, Natowicz MR. Discrimination as a consequence of genetic testing. Am J Hum Genet 1992; 50: 476-482.

19 Surbone A. Genetic medicine: the balance between science and morality. Ann Oncology 2004; 15: i60-i64. 